\title{
Estudio in vitro de permeabilidad, porosidad y crecimiento celular en membranas electrohiladas para prótesis vasculares
}

\author{
Raúl A. Valencia ${ }^{a}, b$, Yuliet Montoya ${ }^{a}$, Simón Sánchez ${ }^{\mathrm{a}}$, Isabel C. Ortiz ${ }^{\mathrm{c}}$, \\ Lina M. Hoyos ${ }^{\mathrm{a}}$ y John Bustamante ${ }^{\mathrm{a}, *}$ \\ a Grupo de Dinámica Cardiovascular, Centro de Bioingeniería, Universidad Pontificia Bolivariana, Medellín, Colombia \\ b Grupo de Automática y Diseño A+D, Universidad Pontificia Bolivariana, Medellín, Colombia \\ c Grupo de Biología de Sistemas, Universidad Pontificia Bolivariana, Medellín, Colombia
}

Recibido el 21 de febrero de 2016; aceptado el 20 de mayo de 2016

Disponible en Internet el 28 de septiembre de 2016

\section{PALABRAS CLAVE \\ Prótesis de vasos \\ sanguíneos; \\ Técnicas de cultivo \\ celular; \\ Permeabilidad; \\ Porosidad; \\ Propiedades de \\ superficie}

\begin{abstract}
Resumen
Introducción y objetivos: En la actualidad la posibilidad de fabricación de implantes vasculares mediante la técnica de electrospinning ha ganado interés para vasos sanguíneos de diámetros pequeños. El potencial en aplicaciones vasculares reside en su capacidad de generar estructuras microporosas con gran área superficial. Sin embargo, poco se conoce del efecto de dicha microestructura y su espesor, tanto en las propiedades de transporte de masa como en la proliferación celular. El propósito de este trabajo es analizar la permeabilidad, la porosidad y el crecimiento celular en membranas electrohiladas para prótesis vasculares.

Métodos: mediante electrohilado se fabricaron membranas para implantes de poliuretano con memoria de forma (Irogran) en dos espesores, muestra 0 entre $0,2 \mathrm{~mm}$ y $0,9 \mathrm{~mm}$ y muestra +1 entre $0,9 \mathrm{~mm}$ y $1,0 \mathrm{~mm}$, sobre las cuales se sembraron fibroblastos cardiacos humanos por un periodo de incubación hasta de 10 días. La porosidad y permeabilidad se evaluaron mediante la norma ISO 7198 y la proliferación celular se analizó a través de microscopia óptica y electrónica de barrido (SEM). El número total de muestras fue 12 para cada espesor de referencia. El análisis de datos se llevó a cabo mediante una prueba tipo ANOVA.

Resultados: las muestras +1 presentaron permeabilidad promedio de $55,5 \%$ menor que las 0 , reducción de la porosidad de 10,24\%, asociado a mayor crecimiento celular, evidenciado por sincitios celulares.
\end{abstract}

\footnotetext{
Abreviaturas: SEM, De sus siglas en inglés, microscopía electrónica de barrido; ISO, De sus siglas en inglés, Organización internacional para estandarización.

Abbreviations: SEM, Scanning Electron Microscopy; ISO, International Organization for Standardization.

* Autor para correspondencia.

Correo electrónico: bustamante.john@gmail.com (J. Bustamante).
} 


\section{KEYWORDS}

Blood vessel grafts;

Cell culture

techniques;

Permeability;

Porosity;

Surface properties
Conclusiones: La variación de estructuras microporosas de gran área superficial para obtener implantes con la técnica de electrospinning, incide en el crecimiento celular y subsecuentemente en la permeabilidad y la porosidad, hecho que abre una gran oportunidad para su uso potencial en aplicaciones vasculares de diámetros pequeños.

(c) 2016 Sociedad Colombiana de Cardiología y Cirugía Cardiovascular. Publicado por Elsevier España, S.L.U. Este es un artículo Open Access bajo la licencia CC BY-NC-ND (http:// creativecommons.org/licenses/by-nc-nd/4.0/).

In vitro permeability, porosity and cell growth study in electrospin membranes for vascular grafts

\begin{abstract}
Introduction and motivation: Nowadays, the possibility of engineering vascular grafts by means of electrospinning has attracted interest for small-diameter blood vessels. Potential vascular application lies in their ability to generate microporous structures with a big surface area. However, little is know about the effect of such microstructure and its thickness, both regarding mass transportation as well as cell proliferation. The motivation of this work is to analyse the permeability, porosity and cell growth in electrospun membranes for vascular grafts.

Methods: by electrospinning membranes for grafts made of memory polyurethane foam were fabricated in two thicknesses, sample 0 between 0.2 and $0.9 \mathrm{~mm}$ and sample +1 between 0.9 and $1.0 \mathrm{~mm}$, amongst which human cardiac fibroblasts were grown during an incubation period of up to 10 days. Porosity and permeability were assessed according to ISO 7198 and cell proliferation was analysed with scanning optical and electronic microscopy (SEM). Total sample number was 12 for each baseline thickness. Data analysis was conducted by ANOVA test.

Results: +1 samples presented an average permeability that was $55.5 \%$ lower than the 0 samples, $10.24 \%$ decrease in porosity associated to bigger cell growth, evidenced by syncytial cells.

Conclusion: The variation of microporous structures of great surface area in order to obtain grafts by means of electrospinning technique affects cell growth and subsequently their permeability and porosity, thus offering an opportunity for its potential use in small-diameter vascular applications.

(c) 2016 Sociedad Colombiana de Cardiología y Cirugía Cardiovascular. Published by Elsevier España, S.L.U. This is an open access article under the CC BY-NC-ND license (http:// creativecommons.org/licenses/by-nc-nd/4.0/).
\end{abstract}

\section{Introducción}

De acuerdo con la Organización Mundial de la Salud (OMS) las enfermedades cardiovasculares son la principal causa de muerte en el mundo ${ }^{1}$. Cada año se estima que alrededor de 17,5 millones de personas mueren a causa de estas patologías, de las cuales el $80 \%$ acaecen en países de bajos y medianos ingresos ${ }^{2}$. En Colombia, entre los años 1998 y 2011 se presentaron 628.630 muertes a causa de las enfermedades cardiovasculares, cifra que representó un 23,5\% del total de fallecimientos reportados en este lapso de tiempo ${ }^{3}$.

Ya que la patología vascular es el compromiso fundamental en gran parte de dicha casuística, se han introducido múltiples tratamientos para este tipo de lesiones, que van desde el uso de medicamentos hasta la ejecución de procedimientos quirúrgicos que requieren la implantación de distintos injertos vasculares ${ }^{4,5}$. Cuando se hace necesario reemplazar un segmento de vaso sanguíneo, se consideran los implantes autólogos, homólogos o heterólogos ${ }^{6}$; sin embargo, en la mayoría de ocasiones esto no es posible ${ }^{7}$, y por tanto se acude al uso de implantes sintéticos ${ }^{8,9}$, que buscan ser funcionalmente similares al vaso sanguíneo ${ }^{10,11}$, lo cual incluye una identidad adecuada del lecho de flujo, para evitar respuestas trombogénicas y de estrés al perderse el tapizado endotelial normal.

Entre los materiales más empleados en prótesis vasculares, se encuentran el politetrafluoroetileno PTFE (Teflón ${ }^{\circledR}$ ), el polietileno tereftalato o PET (Dacrón ${ }^{\circledR}$ ) y los polímeros sintéticos ${ }^{6}$. Por su parte, la ingeniería de tejidos viene centrando su atención en métodos para la fabricación de implantes vasculares sintéticos con matrices poliméricas de forma que interactúen con las células sanguíneas, con el fin de que se reproduzcan y creen una matriz extracelular que conduzca a la formación de nuevo tejido endotelial ${ }^{12,13}$. Una de las alternativas más atractivas para la fabricación de matrices poliméricas es la técnica de electrospinning, dada su capacidad de generar estructuras microporosas, similares a un tejido extracelular y obtener grandes áreas superficiales donde las células se puedan adherir y proliferar. Adicionalmente, se puede controlar el grado de permeabilidad y porosidad, propiedades involucradas en el desempeño de la prótesis $8,9,14,15$.

Así mismo, se resalta esta técnica como una de las opciones para la fabricación de implantes vasculares sintéticos de 


\author{
Glosario de símbolos \\ $k \quad$ Permeabilidad $\left[\mathrm{m}^{2}\right]$

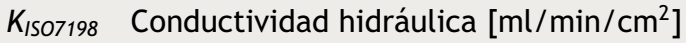 \\ $\mu_{\text {fluido }}$ Viscosidad del fluido de trabajo [Pa*s] \\ $\rho_{\text {fluido }}$ Densidad del fluido de trabajo $\left[\mathrm{kg} / \mathrm{m}^{3}\right]$ para \\ prueba de permeabilidad \\ g Constante gravitacional $\left[\mathrm{m} / \mathrm{s}^{2}\right]$ \\ $\varepsilon \quad$ Porosidad [\%] \\ $w \quad$ Peso seco de la muestra [gr] \\ E Espesor de la muestra [mm] \\ A Área de la muestra $\left[\mathrm{mm}^{2}\right]$ \\ $\rho_{\text {membrana }}$ Densidad aparente de la membrana $\left[\mathrm{g} / \mathrm{cm}^{3}\right]$ \\ $\rho_{L} \quad$ Densidad del fluido de trabajo $\left[\mathrm{g} / \mathrm{cm}^{3}\right]$ para \\ prueba de porosidad \\ $\sigma^{2} \quad$ Varianza \\ W Estadístico de prueba en la distribución $W$ \\ $W_{0.95}$ Valor de $W \operatorname{con} \alpha=0,05$ \\ E Espesor [mm] \\ $P \quad$ Presión [mm Hg] \\ I Horas de incubación \\ FO Valor estadístico en la distribución $F$ \\ Valor-p Estadístico de prueba
}

Tabla 1 Parámetros de operación del equipo de electrospinning para la fabricación de membranas de poliuretano con memoria de forma (Irogran, al $21 \% \mathrm{w} / \mathrm{w}$ en solución de tetrahidrofurano [THF]/dimetilformamida [DMF] al 50\% $\mathrm{w} / \mathrm{w})$

\begin{tabular}{lll}
\hline Parámetros & $\begin{array}{l}\mathrm{E}+1 \\
(0,9 \mathrm{~mm} \leq \\
\mathrm{E}<1,0 \mathrm{~mm})\end{array}$ & $\begin{array}{l}\mathrm{E} 0 \\
(0,2 \mathrm{~mm} \leq \\
\mathrm{E}<0,9 \mathrm{~mm})\end{array}$ \\
\hline $\begin{array}{l}\text { Volumen de } \\
\text { solución/inyectores [ml] }\end{array}$ & 5 & 3,5 \\
$\begin{array}{l}\text { Voltaje [kV] } \\
\text { Distancia }\end{array}$ & 14 & 14 \\
$\quad$ inyectores-colector [cm] & 16 & 16 \\
$\begin{array}{l}\text { Flujo de la bomba [ml/h] } \\
\text { Velocidad del colector [rpm] }\end{array}$ & 0,25 & 0,25 \\
Temperatura $(\mathrm{T})$ [ $\left.{ }^{\circ} \mathrm{C}\right]$ & 10 & 10 \\
Humedad relativa $(\mathrm{Hr})[\%]$ & $60-70$ & $25-35$ \\
Tiempo de operación [h] & 20 & $60-70$ \\
\hline
\end{tabular}

293-230. A cada una de las muestras le tomaron 10 mediciones del espesor y se determinó el promedio.

\section{Preparación de las muestras}

diámetros pequeños $(<5 \mathrm{~mm})^{14,16-18}$. Sin embargo, pese a sus ventajas, cabe resaltar que en este tipo de prótesis vascular aún se desconoce cómo afectan el espesor de la membrana y otras propiedades relacionadas con el transporte de masa en la pared, en la generación de sincitios celulares para la endotelización del implante ${ }^{19}$.

El objetivo de este estudio es analizar la permeabilidad, porosidad y proliferación celular en membranas electrohiladas de poliuretano con memoria de forma, con diferentes espesores para prótesis vasculares.

\section{Métodos}

\section{Fabricación de implantes}

En el Laboratorio de Síntesis de Nanomateriales, Campus Universitario de Laureles, Universidad Pontificia Bolivariana, de Medellín, se fabricaron membranas electrohiladas con diferentes espesores $(E)$, teniendo en cuenta espesores de vasos reales y de implantes vasculares comerciales. Los espesores de membrana fueron seleccionados así: muestra $0: 0,2 \mathrm{~mm} \leq \mathrm{E}<0,9 \mathrm{~mm}$ y muestra $+1: 0,9 \mathrm{~mm} \leq$ $\mathrm{E}<1,0 \mathrm{~mm}$. Para la fabricación de las muestras se empleó como solución base el poliuretano con memoria de forma $\left(\operatorname{Irogran}^{\circledR}\right)$ al $21 \% \mathrm{w} / \mathrm{w}$ en una solución de tetrahidrofurano (THF)/dimetilformamida (DMF) al 50\% w/w. Para el montaje del equipo se emplearon 8 inyectores de $5 \mathrm{ml}$ de volumen tipo $21 \mathrm{G} \times 38 \mathrm{~mm}$, con agujas de $0,8 \mathrm{~mm} \times 1 \frac{1}{2} 2^{\prime \prime}$ con punta recortada. Como colector del material se utilizó un cilindro de aluminio de $1^{\prime \prime}$ de diámetro x $15 \mathrm{~cm}$ de largo en un mandril rotatorio. Para la fabricación de las membranas se emplearon los parámetros que se presentan en la tabla 1. El montaje del equipo se puede observar en la figura 1.

Para determinar el espesor promedio de las muestras, se empleó un micrómetro digital marca Mitutoyo ${ }^{\circledR}$ serie
Las membranas fueron recortadas en fragmentos circulares de $2,2 \mathrm{~cm}$ y $1,2 \mathrm{~cm}$ de diámetro, basado tanto en los requerimientos de los montajes para las pruebas de permeabilidad y porosidad, según la norma ISO 7198, como en los diámetros de los pozos para los cultivos celulares. Las muestras de mayor diámetro fueron utilizadas para las pruebas de permeabilidad, y las otras muestras fueron empleadas en las pruebas de porosidad y análisis óptico. El número total de muestras fue 12 para cada espesor de referencia. Posteriormente, las muestras fueron esterilizadas en óxido de etileno para reducir el riesgo de contaminación.

\section{Modelo in vitro: fibroblastos cardiacos}

Los cultivos celulares fueron llevados a cabo en el Laboratorio para el Procesamiento de Cultivos, Campus Universitario de Robledo, Universidad Pontificia Bolivariana. El modelo in vitro que se utilizó durante los experimentos empleó cultivos de fibroblastos cardiacos humanos de aurícula-NHCF-A (Proveedor Lonza Group Ltda.). Esta línea celular fue aislada de tejido auricular de corazón adulto normal, expresando aproximadamente el $90 \%$ de colágeno tipo ।.

Los cultivos celulares de fibroblastos se mantuvieron en medio de cultivo FGM al $10 \%$ de suero bovino fetal (SBF), suplementado con penicilina $(1.000 \mathrm{U} / \mathrm{ml})$ y estreptomicina $(1.000 \mathrm{~g} / \mathrm{ml})$, a una temperatura de $37^{\circ} \mathrm{C}$, 1 atm de presión, $5 \% \mathrm{CO}_{2}, 95 \% \mathrm{O}_{2}$ y $95 \%$ de humedad relativa. El medio fue cambiado una vez las células alcanzaron una confluencia aproximada entre 88 a 90\%. Para desprender las células se emplearon $3 \mathrm{ml}$ de tripsina EDTA al 0,05\% y se detuvo la tripsinización con $3 \mathrm{ml}$ de medio neutralizante NTS. La solución se centrifugó a 1.200 rpm durante 7 minutos. Seguidamente, se descartó el sobrenadante, se resuspendieron las células en $1 \mathrm{ml}$ de medio de cultivo, y se realizó conteo celular y porcentaje de viabilidad. Finalmente, las células restantes 


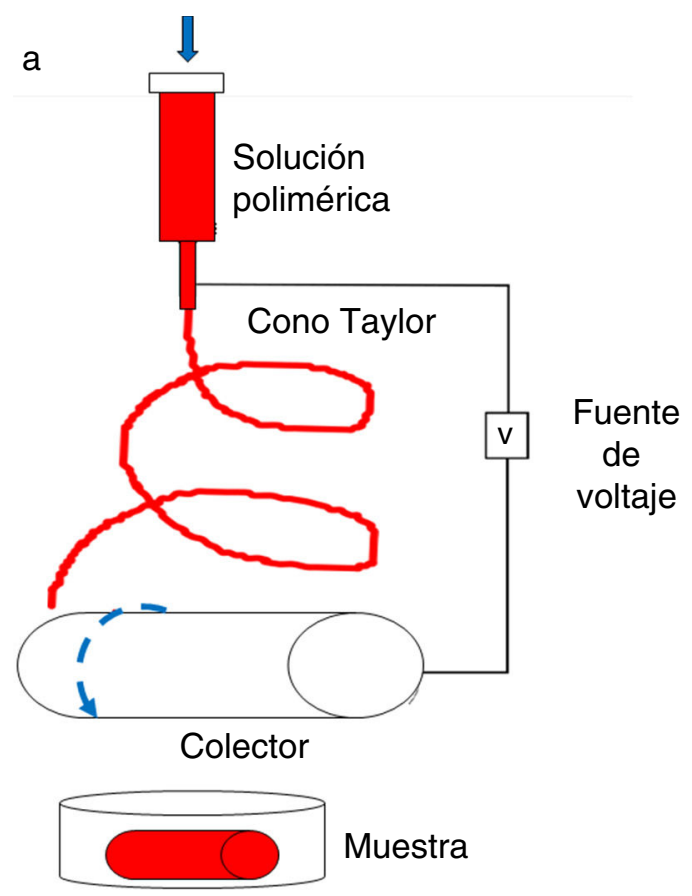

b

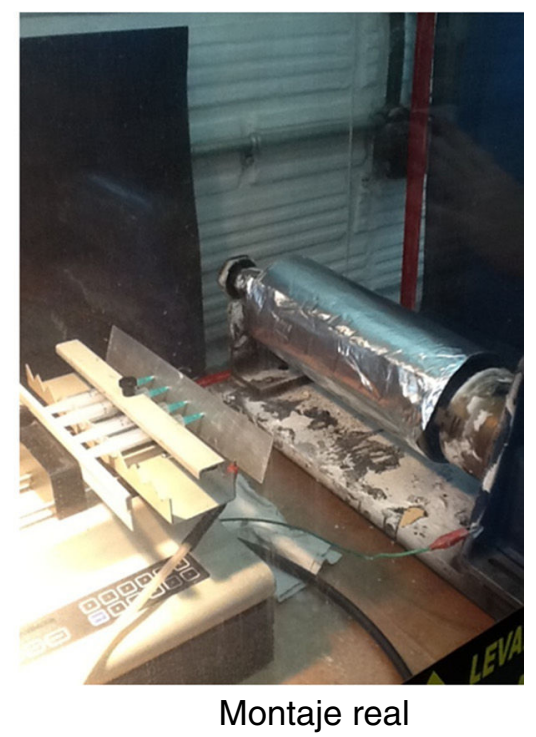

Figura 1 Montaje para la fabricación de las membranas por la técnica de electrospinning. a) Esquema del proceso. b) Montaje físico.

se sub cultivaron en un nuevo recipiente y se llevaron a incubación a $37^{\circ} \mathrm{C}$.

\section{Siembra de células en las membranas}

En platos de cultivo de 6 y 24 pozos se depositaron membranas electrohiladas de las muestras $0 \mathrm{y}+1$, a las cuales se adicionaron $3 \mathrm{ml}$ de medio de cultivo FGM suplementado con suero fetal bovino y antibiótico, y se dejaron suspendidas durante 2 días para reducir el rechazo a la adhesión de los fibroblastos. Una vez transcurridos los 2 días, se cambió el medio de cultivo, y se preparó una solución de 3.500 células $/ \mathrm{cm}^{3}$ (según recomendación del proveedor). Seguidamente, se adicionaron 1,5 y $3 \mathrm{ml}$ de la solución celular en las cajas de 6 y 24 pozos, respectivamente. Finalmente, las cajas fueron llevadas bajo condiciones controladas, a una temperatura de $37{ }^{\circ} \mathrm{C}, 5 \% \mathrm{CO}_{2}$ y $95 \%$ humedad relativa. Se dejaron incubando por un periodo hasta de 10 días, retirando tres especímenes de cada muestra 0 y +1 a las 48,96 , 192 y 240 horas, para medición y análisis de las variables de estudio.

\section{Análisis de crecimiento celular}

Las membranas se depositaron en un procesador de tejidos durante un periodo de 48 horas, inmersas en alcohol al $50 \%, 70 \%$ y $80 \%$, formol al $10 \%$, tres xiloles y dos parafinas líquidas a $60^{\circ} \mathrm{C}$. Luego de dejar las membranas 12 horas en cada medio, se pasaron a la central de inclusión para formar bloques de parafina que fueron cortados en un micrótomo, marca Leyca ${ }^{\circledR}$ serie RM2235, en el cual se practicaron cortes de 3 micras de espesor con una cuchilla de alto perfil. Finalmente, se fijaron y colorearon las placas con hematoxilina-eosina y se observaron por microscopia óptica.

\section{Medición de permeabilidad}

Para la medición de la permeabilidad estática se empleó el procedimiento descrito en la norma ISO $7198^{20}$. El montaje consistió en una columna de presión hidrostática, con una altura de líquido equivalente a una presión desde 0 a $150 \mathrm{~mm}$ $\mathrm{Hg}$. Como fluido de trabajo se empleó agua desionizada para evitar el taponamiento de los microporos.

En los ensayos se emplearon las muestras $0 \mathrm{y}+1$ a 48 , 96, 192 y 240 horas de incubación celular. A cada muestra analizada se le determinó la permeabilidad estática a $80 \mathrm{~mm}$ $\mathrm{Hg}, 120 \mathrm{~mm} \mathrm{Hg}$ y $150 \mathrm{~mm} \mathrm{Hg}$.

Los resultados obtenidos se reportaron en unidades de $\mathrm{ml} / \mathrm{min} / \mathrm{cm}^{2}$, que corresponden a la conductividad hidráulica de la muestra, la cual mediante la ecuación siguiente se transcribe en términos de permeabilidad.

$k=\frac{K_{\text {lSO7198 }} \times \mu_{\text {fluido }}}{\rho_{\text {fluido }} \times g} \times \frac{1}{6000}$

Donde

$k=$ Permeabilidad $\left[\mathrm{m}^{2}\right]$.

$K_{\mathrm{IS} 07198}=$ Conductividad hidráulica $\left[\mathrm{ml} / \mathrm{min} / \mathrm{cm}^{2}\right]$.

$\mu_{\text {fluido }}=$ Viscosidad del fluido de trabajo [Pa*s] .

$\rho_{\text {fluido }}=$ Densidad del fluido de trabajo $\left[\mathrm{kg} / \mathrm{m}^{3}\right]$. $\mathrm{g}=$ Constante gravitacional $\left[\mathrm{m} / \mathrm{s}^{2}\right]$. 


\section{Medición de porosidad}

Se hizo con la técnica de gravimetría mediante el procedimiento indicado en la norma ISO 7198. En esta prueba se emplearon las muestras 0 y +1 a 48, 96, 192 y 240 horas de incubación celular. La porosidad se determinó mediante la siguiente ecuación.

$\varepsilon=100 \times\left(\frac{1-\frac{w}{E \times A}}{\rho_{\text {membrana }}} \times 1000\right)$

Donde

$\varepsilon=$ Porosidad [\%].

$W=$ Peso seco de la muestra [g].

$E=$ Espesor de la muestra $[\mathrm{mm}]$.

$A=$ Área de la muestra $\left[\mathrm{mm}^{2}\right]$.

$\rho_{\text {membrana }}=$ Densidad aparente de la membrana $\left[\mathrm{g} / \mathrm{cm}^{3}\right]$.

Para la medición de la densidad aparente de la muestra, se empleó una balanza densimétrica calibrada con alcohol isopropílico $\left(\rho_{L}=0,785 \mathrm{~g} / \mathrm{cm}^{3}\right)$ como líquido de trabajo. El procedimiento se basó en la medición del peso seco de la muestra, seguido de la medición del peso húmedo tras sumergir la muestra en el líquido de trabajo. La densidad aparente se determinó con la siguiente ecuación.

$\rho_{\text {membrana }}=\left(\frac{\rho_{L} \times W}{W-W_{W E T}}\right)$
Donde

$\rho_{L}=$ Densidad del fluido de trabajo $\left[\mathrm{g} / \mathrm{cm}^{3}\right]$.

$W_{W E T}=$ Peso húmedo de la muestra $[\mathrm{g}]$.

Por otra parte, para obtener un valor exacto del área de las muestras, se procedió a analizarlas mediante el software Image ${ }^{\circledR}$.

\section{Análisis por microscopia óptica y electrónica de barrido SEM}

Las membranas de las muestras $0 \mathrm{y}+1$ sometidas a los periodos de incubación celular, se fijaron en una solución de formaldehído al $10 \%$ en solución buffer de fosfato (PBS) por un periodo de 24 horas. Las muestras se prepararon para análisis de microscopia óptica y para análisis SEM.

Para las muestras de microscopia óptica, se procedió a teñir con hematoxilina-eosina, y con la ayuda de un microscopio marca Motic ${ }^{\circledR}$ serie ECO-BINO y una cámara digital se registraron imágenes del crecimiento celular en cada una de las muestras.

Las muestras destinadas al análisis SEM se deshidrataron en baños sucesivos de alcohol a concentraciones de $50 \%$, $70 \%$, $85 \%$ y $96 \%$. Una vez deshidratadas, estas fueron montadas en una placa de aluminio y recubiertas con una película de oro; posteriormente fueron analizadas.
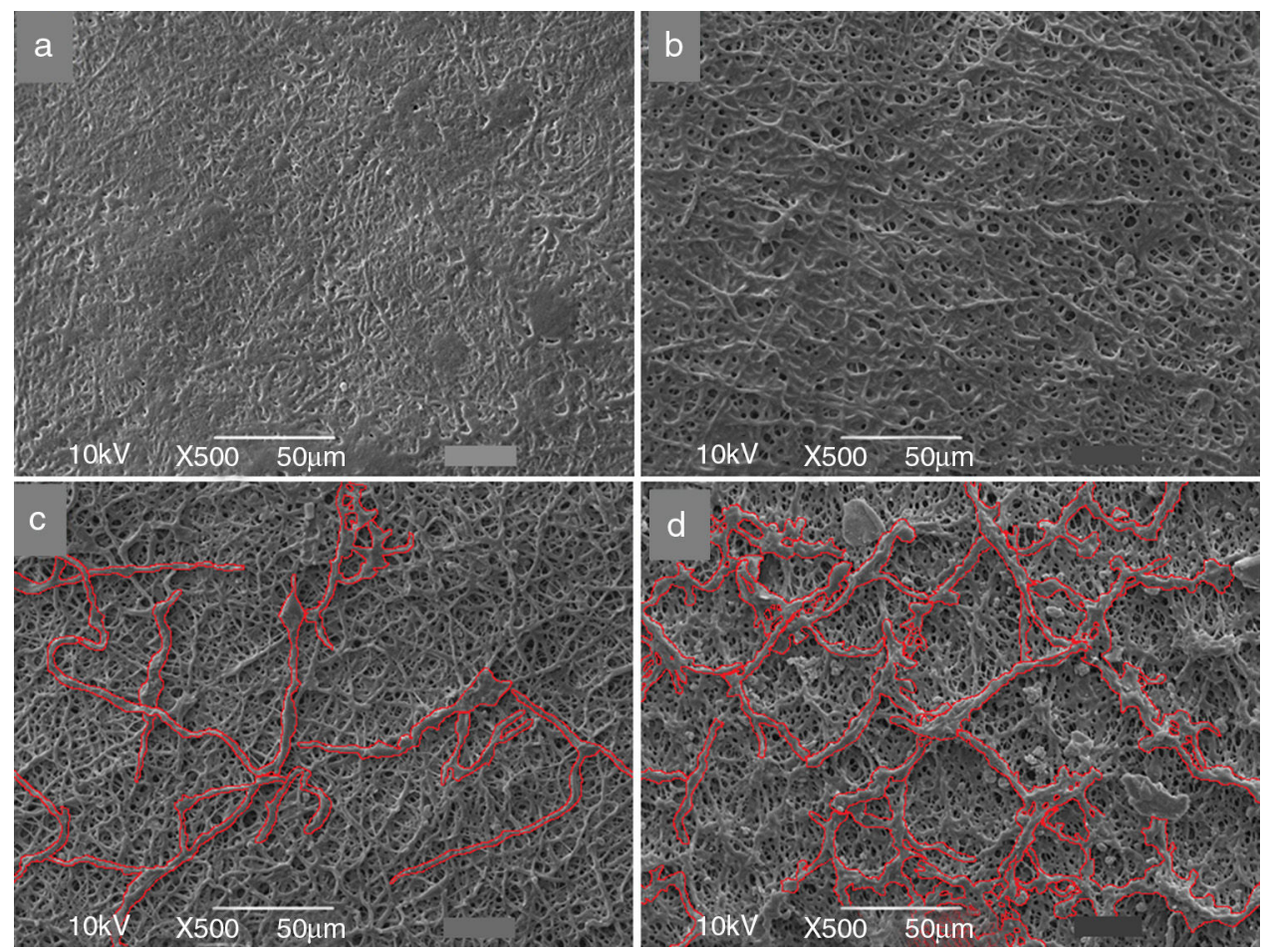

Figura 2 Imágenes tomadas mediante microscopia electrónica de barrido (SEM) de las membranas electrohiladas. a) Muestra 0, sin células. b) Muestra +1 , sin células. c) Muestra 0, con 240 horas de incubación. d) Muestra +1 , con 240 horas de incubación. En rojo se resaltan las células presentes en las muestras respectivas. 

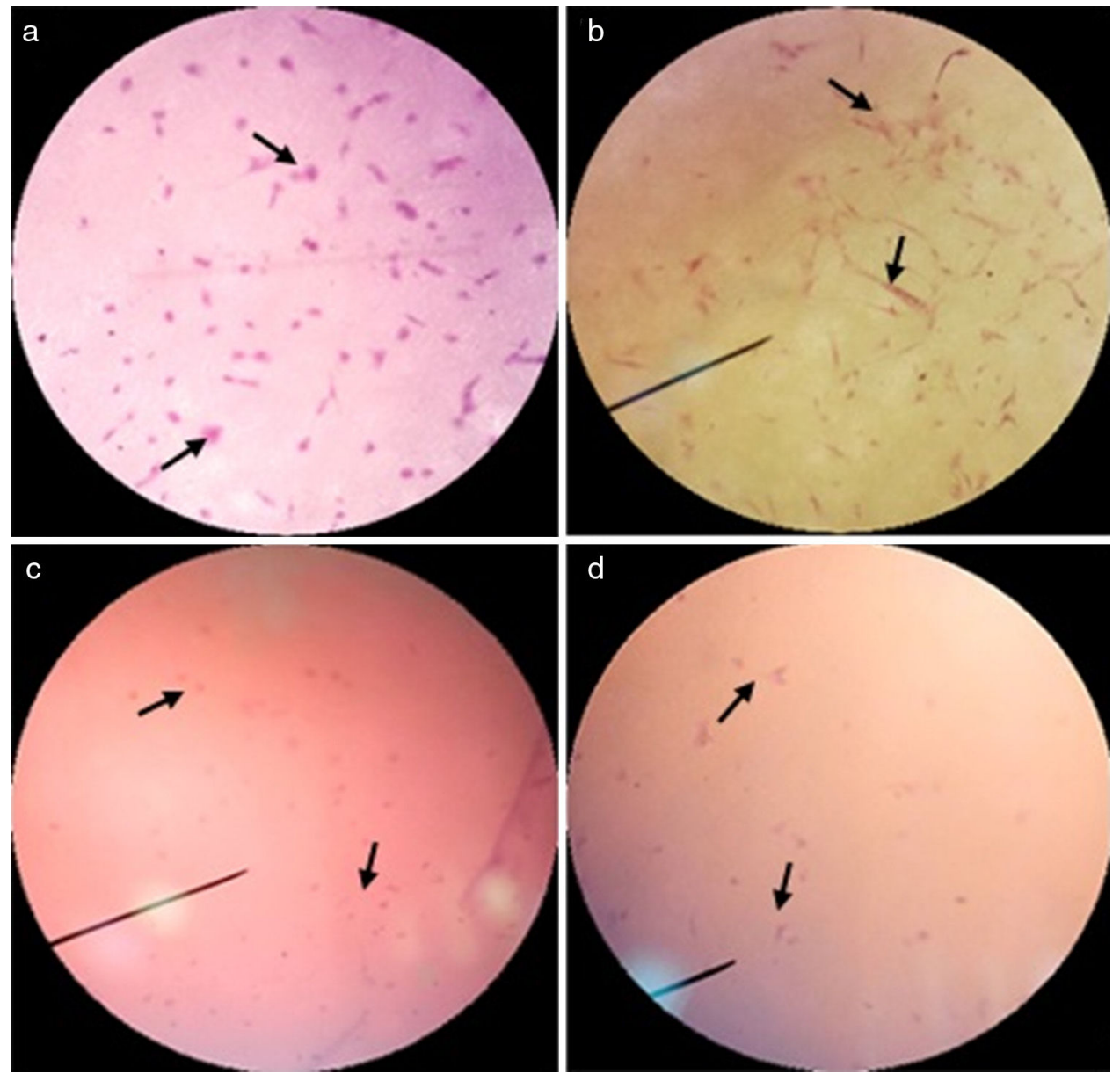

Figura 3 Imágenes por microscopia óptica a campo claro a 10X de muestras a diferentes horas de incubación. a) Muestra 0 a 48 horas. b) Muestra 0 a 240 horas. c) Muestra +1 a 48 horas. d) Muestra +1 a 240 horas. Las flechas resaltan los sincitios celulares presentes en las muestras.

\section{Análisis estadístico}

Inicialmente se determinó la normalidad de los datos mediante la prueba de Shapiro-Wilks. El análisis de los datos de la permeabilidad y porosidad en las muestras se llevó a cabo mediante los análisis estadísticos ANOVA, para determinar la influencia de cada una de las variables, y su relación con las propiedades de interés del estudio ${ }^{21}$.

\section{Resultados}

\section{Proliferación celular}

En la figura 2 se presentan las micrografías mediante microscopia óptica y electrónica de barrido SEM de especímenes sin y con siembra de fibroblastos cardiacos humanos, para ambas muestras $0 y+1$. En estas imágenes se pueden apreciar las células adheridas, conformando sincitios en la superficie de la membrana electrohilada.

En la figura 3 se presentan las micrografías de las muestras con distintas horas de incubación, teñidas con hematoxilina-eosina, lo cual permite observar presencia de núcleos y citoplasmas celulares intactos sobre las muestras de estudio, elemento indicador de viabilidad celular. Adicionalmente, en la figura 4 se presentan colonias celulares dentro de la pared, evidenciando penetración celular.

\section{Permeabilidad y porosidad}

Los resultados de mediciones de permeabilidad y porosidad para las muestras $0 \mathrm{y}+1$, según las horas de incubación, se presentan en las figuras 5 y 6 . Al comparar estas figuras se observa que para las muestras +1 a 48 y 96 horas de incubación celular, la permeabilidad promedio fue superior en $35,2 \%$ y $46,3 \%$ respectivamente, en comparación con las mismas muestras 0 . Así mismo, cuando se compararon los resultados a 192 y 240 horas de incubación, se observó lo contrario; las muestras +1 tuvieron una permeabilidad promedio menor en 20,3 y $55,5 \%$ respectivamente, en comparación con las muestras 0 . Se analizó la variación en la permeabilidad respecto a las horas de incubación, a presiones de $80 \mathrm{~mm} \mathrm{Hg}$ y $150 \mathrm{~mm} \mathrm{Hg}$ (figura 7).

Seguidamente, la porosidad de las muestras +1 , evidenció que la razón de disminución con los días de incubación fue 

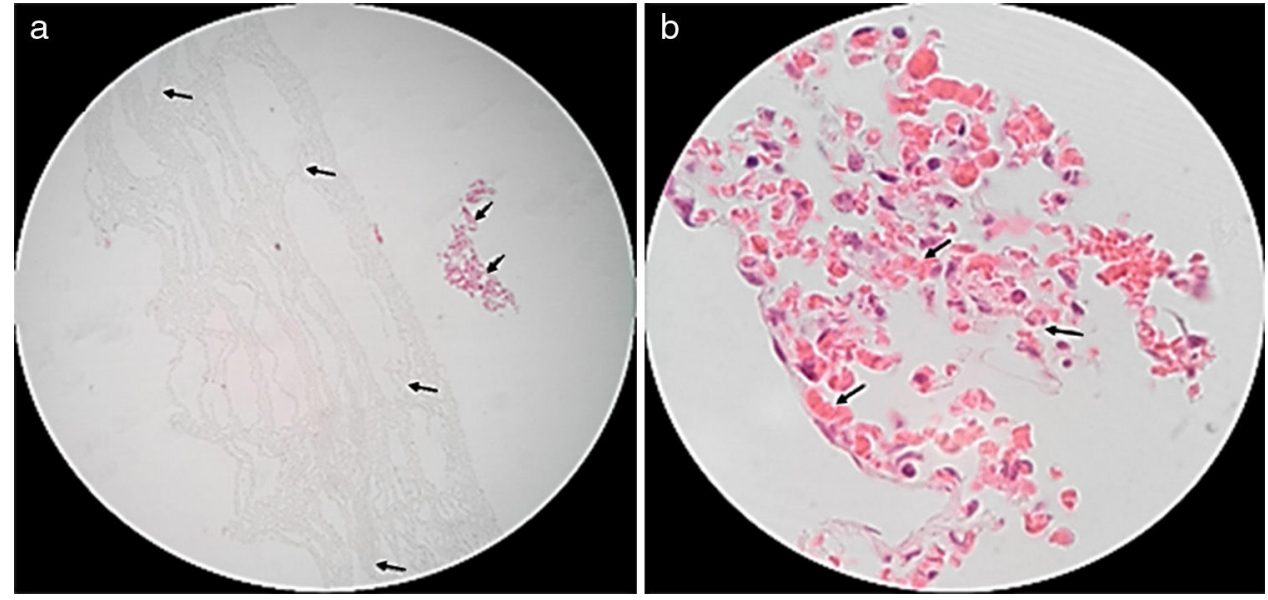

Figura 4 Imágenes por microscopia óptica a campo claro por corte anatomopatológico, a 240 horas de incubación. a) Muestra +1 a 10X. b) Muestra +1 a 100X. Las flechas resaltan la membrana y las colonias celulares presentes en las muestras.

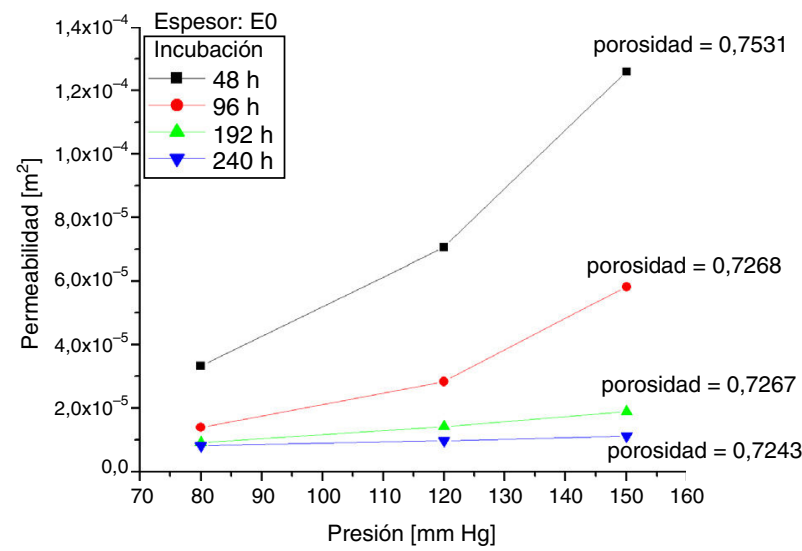

Figura 5 Datos de permeabilidad y porosidad a diferentes presiones y horas de incubación para las muestras 0 .

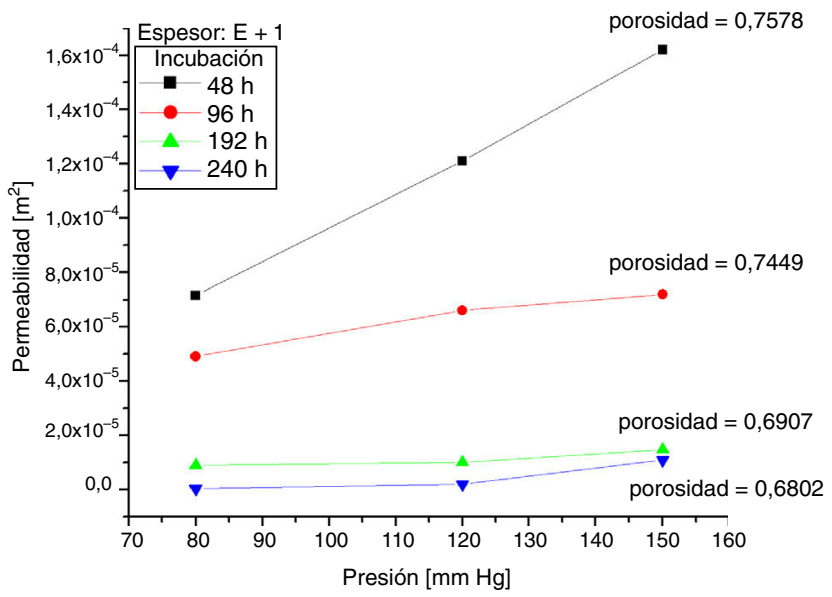

Figura 6 Datos de permeabilidad y porosidad a diferentes presiones y horas de incubación para las muestras +1 .

mayor, alcanzando hasta un 10,24\% cuando se comparó en un periodo de incubación entre 48 y 240 horas, mientras que para las muestras 0 , la disminución fue de $3,86 \%$ en el mismo periodo de incubación.

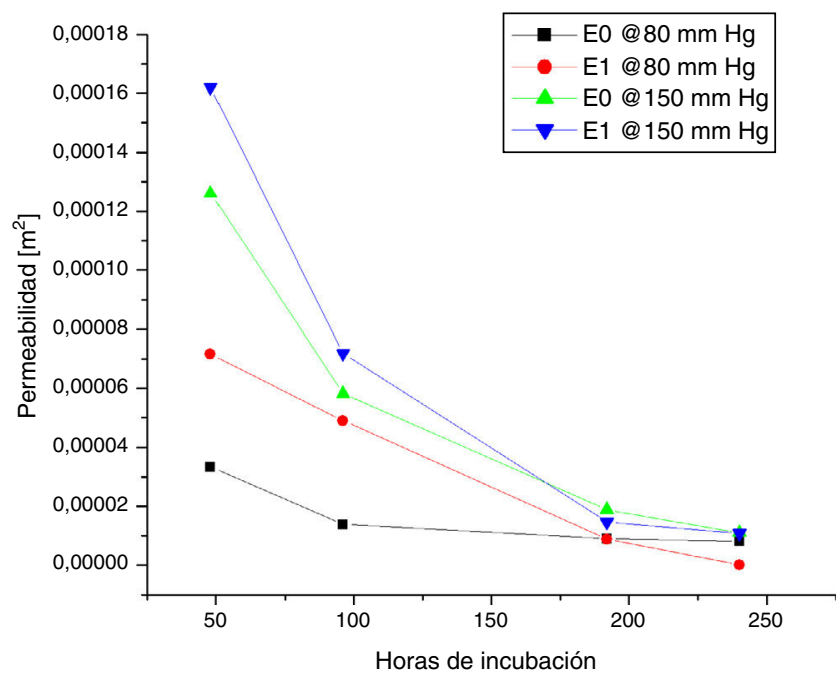

Figura 7 Variación de la permeabilidad con las horas de incubación a $80 \mathrm{~mm} \mathrm{Hg}$ y $150 \mathrm{~mm} \mathrm{Hg}$.

\section{Prueba ANOVA}

Previamente se probó las hipótesis de normalidad mediante la prueba de Shapiro-Wilks, cuyos resultados se pueden observar en la tabla 2.

A los datos de permeabilidad se les realizó un análisis estadístico tipo ANOVA (tabla 3). En este análisis el valor-p (columna 6), es menor al de $\alpha$, de ahí que el efecto de la variable es significativo o relevante en la experimentación. En el análisis ANOVA, el resultado "significativo" quiere decir que el efecto provocado por la variable o combinación de ellas tiene influencia sobre la permeabilidad.

\section{Discusión}

Las membranas electrohiladas abren la posibilidad de la construcción de implantes vasculares con características específicas de acuerdo con las funcionalidades pretendidas. En las prótesis vasculares se puede promover la generación 
Tabla 2 Resultados de la prueba de Shapiro-Wilks para normalidad de los datos obtenidos en la prueba de permeabilidad para ambos espesores

\begin{tabular}{lllllll}
\hline Muestra & \# de muestras & $\sigma^{2 a}$ & $W^{b}$ & $W_{0,95}{ }^{c}$ & Prueba & Resultado \\
\hline$(+1)$ & 12 & 7,656 & 0,851 & 0,988 & $W_{0,95}>W$ & Datos normales \\
$(0)$ & 12 & 3,575 & 0,346 & 0,988 & $W_{0,95}>W$ & Datos normales \\
\hline
\end{tabular}

a $\sigma^{2}=$ Varianza.

b $W=$ Estadístico de prueba en la distribución $W$.

c $W_{0,95}=$ valor de $W \operatorname{con} \alpha=0,05$.

Tabla 3 Análisis ANOVA de los datos de permeabilidad

\begin{tabular}{lclllll}
\hline \multicolumn{7}{c}{$\alpha=0,05$} \\
\hline Fuente & $S C^{\text {a }}$ & $G L^{\text {b }}$ & $C^{c}$ & $F^{\text {d }}$ & Valor-p & Resultado \\
\hline Efecto $E$ & 18,83 & 1 & 18,83 & 452,4 & $1,23 E-29$ & Significativo \\
Efecto $P$ & 81,14 & 2 & 40,57 & 974,6 & $1,78 \mathrm{E}-46$ & Significativo \\
Efecto I & 393,0 & 4 & 98,27 & 2360 & $3,15 \mathrm{E}-65$ & Significativo \\
Efecto E-P & 11,87 & 2 & 5,938 & 142,6 & $1,57 \mathrm{E}-23$ & Significativo \\
Efecto E-I & 295,0 & 4 & 73,77 & 1772 & $1,60 \mathrm{E}-61$ & Significativo \\
Efecto P-I & 54,77 & 8 & 6,846 & 164,4 & $7,3 \mathrm{E}-38$ & Significativo \\
Efecto EPI & 26,18 & 8 & 3,272 & 78,62 & $6,6 \mathrm{E}-29$ & Significativo \\
Error & 2,49 & 60 & 0,042 & 1 & - & - \\
Total & 883,4 & 89 & 9,926 & 238,4 & - & - \\
\hline
\end{tabular}

Donde:

$E=$ Espesor

$P=$ Presión

$I=$ Horas de incubación

a $S C=$ suma de cuadrados;

b $G L=$ grados de libertad;

c $C M=$ cuadrado medio;

d $F O=$ valor estadístico en la distribución $F$;

e valor- $p=$ estadístico de prueba.

de sincitios celulares. Los resultados de este estudio mostraron que en las muestras +1 , el crecimiento de tejido celular era de mayor proporción frente a las muestras 0 , conllevando a una caída en los valores de permeabilidad. Una causa posible de la alta proliferación celular en las membranas de mayor espesor serían los valores altos de porosidad de las muestras +1 antes de ser celularizadas, fenómeno que promovió un crecimiento celular significativo en el periodo de incubación analizado.

Se observó una diferencia marcada entre los valores de permeabilidad de la membrana para ambas muestras +1 y 0 a presiones de 80 y $150 \mathrm{~mm} \mathrm{Hg}$, cuando se contrastaron los periodos antes y después de ser celularizadas con los fibroblastos cardiacos. Sin embargo, a las 240 horas, el efecto del espesor y la presión sobre la permeabilidad de la membrana no cambió respecto al anterior; este comportamiento probablemente se debe a que el espacio libre de la membrana ya había sido ocupado por los fibroblastos en las primeras horas y no hay marcado crecimiento posterior o descelularización, de otro lado.

Finalmente, la variable de mayor influencia es la que se relaciona con las horas de incubación de fibroblastos cardiacos, que tiene que ver con el mayor crecimiento celular. Con el uso de materiales nanoestructurados, conformando membranas electrohiladas, el tapizado de cultivo celular hace evidente la creación de una capa celularizada.

\section{Conclusiones}

Las membranas electrohiladas de las muestras +1 presentaron mayor proliferación y generación de sincitios celulares. Esta respuesta se ve traducida en una disminución en la porosidad y permeabilidad con las horas de incubación. Luego de 10 días de incubación se presenta un tapizado de cultivo celular, lo cual hace evidente la creación de una capa celularizada en el interior del implante.

La observación de colonias celulares evidencia que este tipo de membranas predispone a la seudoendotelización del implante vascular, un tema que abre expectativas terapéuticas en patologías cardiovasculares.

Enmarcado en estos resultados preliminares, el trabajo a futuro será considerar otros tipos de matrices poliméricas sintéticas, y evaluar la interacción de la capa celular depositada en el polímero y el flujo, bajo condiciones dinámicas. 


\section{Responsabilidades éticas}

Los autores declaran que para esta investigación no se han realizado experimentos en seres humanos ni en animales. Para este estudio se empleó una línea celular comercial de fibroblastos humanos. Para el trabajo con la presente línea celular se obtuvo la aprobación del Comité de Ética de Investigación en Salud de la Universidad Pontificia Bolivariana, mediante Acta fechada junio 22 de 2015, en apoyo al proyecto investigativo marco en el estudio de biocompatibilidad de nanoestructuras en microambientes de cocultivos de células cardiacas.

\section{Conflicto de intereses}

Los autores declaran no tener relación, condición o circunstancia que constituya un potencial conflicto de intereses.

\section{Agradecimientos}

Agradecimientos expresos al Departamento de Ciencias, Tecnología e Innovación COLCIENCIAS, Colombia, por el soporte becario en la formación de recurso humano. Igualmente a las Universidades Pontificia Bolivariana y EAFIT, Colombia, por el apoyo en la formación de recurso humano comprometida en la presente labor investigativa.

\section{¿Qué se sabe del tema?}

- La patología vascular conlleva la necesidad de contar con vasos protésicos.

- Las prótesis vasculares reemplazan la condiciones de flujo dadas en el árbol vascular.

- Los implantes sintéticos carecen de tapizado celular por lo que difieren en la relación fluido-sanguíneopared.

\section{¿Qué aporta novedad?}

- Las membranas electrohiladas permiten la construcción de implantes vasculares.

- En las prótesis vasculares se puede promover la generación de sincitios celulares.

- Con material nanoestructurado, conformando membranas electrohiladas, el tapizado de cultivo celular hace evidente la creación de una capa celularizada en el interior del implante.

- La observación de colonias celulares evidencia la posibilidad de llegar a la seudoendotelización del implante vascular, un tema que abre expectativas terapéuticas en patologías cardiovasculares.

\section{Bibliografía}

1. OMS. (01 de 2015). Organización Mundial de la Salud. Cardiovascular Diseases. [En línea]. Disponible en: http://www. who.int/mediacentre/factsheets/fs317/es/

2. Fang N, Jiang M, Fan Y. Ideal cardiovascular health metrics and risk of cardiovascular disease or mortality: A meta-analysis. Int J Cardiol. 2016;214:279-83.

3. Boletín №3. Instituto Nacional de Salud de Colombia. Bogotá: Observatorio Nacional de Salud; 2014.

4. Healthline. Ischemic Cardiomyopathy. [Acceso 18 Mar 2015] [En línea] http://www.healthline.com/health/ischemiccardiomyopathy\#Treatment5

5. Machy D, Carteron P, Jozefonvicz J. A new vascular polyester prosthesis impregnated with cross-linked dextran. J Biomater Sci Polym. 2002;13:963-75.

6. Tura A. Vascular grafts. Experiment and modelling. Southhampton, United Kingdom: WIT Press; 2003.

7. Bergemeister H, Strobl M, Grasl C, Liska R, Schima H. Tissue engineering of vascular grafts. Eur Surg. 2013;45:187-93.

8. Barrows TH. Degradable implant materials: a review of synthetic absorbable polymers and their applications. Clin Mat. 1986;1:233-57.

9. Hirt M, Hansen A, Eschenhagen T. Cardiovascular tissue engineering: estate of art. Circ Res. 2014;114:354-67.

10. FDA. Guidance for Industry and FDA Staff. Guidance document for Vascular Prostheses 510(k). 2012. Submissions. Disponible en: http: //www.fda.gov/Medic

11. Greenhalgh E, Dunn M. Modelling blood flow through vascular grafts C98-P01. Philadelphia College of Textile and Science; 1998.

12. Szentivanyi A, Chakradeo T, Zernetsch H, Glasmacher B. Electrospun cellular microenviromental: Understending controlled release and Scaffold structure. Advanced Drug Delivery Review. 2011;63(4-5):209-20.

13. Wade RJ, Burdick JA. Advances in nanofibrous scaffolds for biomedical applications: From electrospinning to self-assembly. Nanotoday. 2014;9:722-42.

14. Chung S, Ingle NP, Montero GA, Kim SH, King MW. Bioresorbable elastomeric vascular tissue engineering scaffolds via melt spinning and electrospinning. Acta Biomaterialia. 2010;6:1958-67.

15. Nabovati A, Llewellin EW, Sousa AC. Through-thickness permeability prediction of three-dimensional multifilament woven fabrics. Composites Part A. Applied Science and Manufacturing. 2010;41:453-63.

16. Bergmeister H, Strobl M, Grasl C, Liska R, Schima H. Tissue engineering of vascular grafts. Eur Surg. 2013;45:187-93.

17. Hasan A, Memic A, Annabi N, Hossain M, Paul A, Dokmeci MR, et al. Electrospun scaffolds for tissue engineering of vascular grafts. Acta Biomaterialia. 2014;10:11-25.

18. Kucinska-Lipka J, Gubanska I, Janik H, Sienkiewicz M. Fabrication of polyurethane and polyurethane based composite fibers by the electrospinning technique for soft tissue engineering of cardiovascular system. Material Science and Engineering:C. 2015;46:166-76.

19. Wang J, Shah A, Yu X. The influence of feber thickness, wall thickness and gap distance on the spiral nanofibrous scaffolds for bone tissue engineering. Material Science and Engineering C. 2011;31:50-6.

20. International standard ISO/DIS 7198, Cardiovascular implants; Tubular vascular prostheses; 1998.

21. Pulido HG, Salazar Rd. Cápitulo 5. Diseños Factoriales. Análisis y diseño de experimentos. (Tercera ed.). México D.F, México: McGraw-Hill; 2012. p. 115-48. 